World Lumen Congress 2021 | May 26-30, 2021 |

lasi, Romania

\title{
Adult Learning Methods in Health Education Institutions
}

Cristina VIRAG-IORGA, Cristian-Silviu BANACU

https://doi.org/10.18662/wlc2021/72

How to cite: Virag-Iorga, C., \& Banacu, C.-S. (2021). Adult Learning Methods in Health Education Institutions. In A. Sandu (vol. ed.), Lumen Proceedings: Vol. 17 World Lumen Congress 2021 (pp. 714-722). Iasi, Romania: LUMEN Publishing House. https://doi.org/10.18662/wlc2021/72 


\title{
Adult Learning Methods in Health Education Institutions
}

\author{
Cristina VIRAG-IORGA ${ }^{1}$, Cristian-Silviu BANACU²
}

\begin{abstract}
The research aims to identify learning styles in health education institutions. The analysis was applied in post-secondary health schools, identifying in addition to the general characteristics of the group, particular aspects of the Kolb model, which determines the belonging to a learning style.

The research tool used was Kolb's questionnaire, it was applied in two health education units, in order to be able to capture possible differences between the learning styles present in the respondents of the general nurse specialization. It should be noted that the emphasis was on the four learning styles present in Kolb's model, as this model is the best known and it is still widely used in research.

The study highlighted the fact that there is a diversity of learning styles identified within these health education institutions that depend to a greater or lesser extent on the age of the respondents.

This research can be extended, being able to be applied in several post-secondary health education units in order to increase the degree of accuracy, the study can be carried out both in state or private health education units, thus increasing the complexity and will be able to obtain even more relevant results.
\end{abstract}

Keywords: Learning, learning style, adults, bealth education, general nurse.

\section{Introduction}

Learning is the process that manifests itself from birth and continues throughout life, it is the most important way to develop individuals. The learning process involves all the components of the human self, motivation, intelligence and personality, generates progress and results that determine the personal development of each individual, as well as the collective growth of the social level of groups of people.

Therefore, learning is a systematic, coordinated activity, which is carried out in an organized framework, aimed at assimilating knowledge and shaping psychic and personality structures. This way of presenting frames the learning process in a way of training, the beneficiaries reaching to form certain knowledge and skills

\footnotetext{
${ }^{1} \mathrm{PhD}$, Bucharest University of Economic Studies, Bucharest, Romania. iorga.cristina@yahoo.com.

2 University Professor PhD, Bucharest Academy of Economic Studies, Bucharest, Romania. cristian.banacu@man.ase.ro
} 
specific to their level of study.

Learning is a "relatively stable change of behavior achieved in the context of the experience in the active confrontation of the individual with his environment" (Negovan, 2006, p.14), or as Sălăvăstru, D., (Sălăvăstru, 2004, p. 15), "Learning must lead not to simple accumulations of information, but to the formation of orientation capacities, thinking and creativity, the flexibility of cognitive and attitudinal structures, in order to allow an optimal adaptation of the rapid changes that they face".

The diversity of learning methods and the way each individual assimilates knowledge, have determined a series of learning styles, these being different from person to person, and may even determine in the future learning a behavior necessary for leadership functions.

In addition, the identification of the predominant learning styles in individuals is important in order to be able to be capitalized in the educational process, thus being able to develop a series of abilities, aptitudes and competences necessary for the professional future of the student.

We can emphasize that the learning style is rather "a mental strategy or a behavior frequently applied in learning situations, built according to one's own potential, especially in an educational context" (Ciesielski, 2009).

Therefore, learning styles represent the personal way of each individual to assimilate knowledge and how to approach the processes associated with learning. At the same time, even if the learning styles are unique, they can be grouped into general categories.

Kolb's model was published in 1984 in his book "Experiential Learning: Experience as the Source of Learning and Development" (Kolb, 1984), where he considered learning styles as being cyclical, providing a definition of learning as a series of multiple experiences. This model is even nowadays used as an organizational tool that can establish the learning styles of adults.

In Kolb's view, learning styles are divided into four levels:

- Through concrete experience;

- Through reflective observation;

- Through abstract conceptualization;

- Through active experimentation.

Kolb's theory of experiential learning is divided on two levels: a four-stage learning cycle and another four separate learning styles. Kolb's theory is dealing with the person's internal cognitive processes.

Kolb states that learning is obtaining of abstract concepts that can be expressed in a flexible way in a number of situations. In Kolb's theory, the desire to achieve new concepts is given by new feelings( McLeod, 2017). The four stages of the Kolb cycle are:

- $\mathrm{CE}$ - concrete experience;

- $\mathrm{RO}$ - refletive observation;

- AC - abstract conceptualization; 
- AE - active experimentation.

The stages follow each other, as in a circle, in which learning can begin at any of the points, provided as long as all four stages are completed.

The learning style is in fact an accumulation of preferences for certain stages of the learning cycle, from the combination of scores, two by two, we can identify four types specific to learning styles, namely:

1. Accommodator - combines CE stages - concrete experience and AE active experimentation;

2. Divergent - combines the stages of CE - concrete experience and RO reflective observation;

3. Convergent - combines AC stages - abstract conceptualization and AE - active experimentation;

4. Assimilator - combines the stages of AC - abstract conceptualization and $\mathrm{RO}$ - reflective observation.

Kolb's model has a very important role in identifying learning styles, being used even today to frame adults in a certain style.

\section{Methodology}

The research aims to identify the predominant learning styles within postsecondary education institutions and their impact on the future profession of general nurse. The research is an empirical one following as anobjective the identification of learning styles for the student's in post-secondary education institutions based on age and the influence of age in choosing a learning style.

This study works based on the following hypothesis:

We estimate that there are differences in learning styles amongst the persons with different ages. This will also influence the educational process of preparing the future medical nurses, age being a factor for adapting the learning process.

The research tool used was the questionnaire, it was anonymous and was applied in two post-secondary health schools to students who wanted to participate in this study.

\subsection{Materials}

The respondents who participated in this study were future nurses, the group being composed of:

- women and men with the specialization of general nurse;

- both from urban and rural areas;

- with various ages;

\subsection{Methods}

We used as a research tool - the questionnaire, it was composed of two parts: the first part highlights the characteristics of the group (age, gender, background) and the second part surprises the questionnaire on learning styles designed by Kolb. 
A number of 48 questionnaires were applied to the students of the general nurse specialization (AMG), at random. The questionnaire was administered individually, with a mean response time of 10 minutes.

The group of students in the study was assessed in terms of the following learning styles specific to Kolb's questionnaire: accommodating, divergent, convergent and assimilating.

The Kolb learning style assessment questionnaire consists of 12 items with four answer options: 1 - it suits me the least, 2- it suits me a little, 3 - it suits me well and 4 - it suits me perfectly. The totalization of the answer variants is done by summing the columns, obtaining a specific score for each column.

\section{Results}

The research was carried out in two pre-universitary education units in Bucharest (in order to maintain confidentiality, we noted the institutions with letters $\mathrm{A}$ and $\mathrm{B})$. The questionnaires were applied in physical form to each individual in the research.

The characteristics of the batch are presented in the table below:

- Age;

- Gender;

- Environment.

Table 1. Batch characteristics

\begin{tabular}{l|c|c|c}
\hline \multicolumn{2}{l|}{$\begin{array}{l}\text { Group of students - adults, } \\
\text { General nurse specialization }\end{array}$} & $\begin{array}{c}\text { Percentage } \\
\text { Post-secondary health } \\
\text { school - A }\end{array}$ & $\begin{array}{c}\text { Percentage } \\
\text { Post-secondary health } \\
\text { school - B }\end{array}$ \\
\hline \multirow{2}{*}{ Age } & $18-25$ years & $25 \%$ & $50 \%$ \\
& $26-35$ years & $25 \%$ & $29 \%$ \\
Gender & $36-45$ years & $33 \%$ & $17 \%$ \\
\hline Environment & Fer 45 years & $17 \%$ & $4 \%$ \\
\hline
\end{tabular}

Source: author's own design

We note from the table above that the general nurse specialization in both schools participating in the study has an affinity for females. Regarding the environment of origin, we can observe that both schools within the study have as 
majority participants in the didactic activity individuals coming from the urban environment.

Regarding the age, we notice that school A has a majority of people between 36-45 years old, while in school B we can observe a predominance of age between 18-25 years old, which highlights that the respondents of post-secondary health school A are more experienced than those in post-secondary health school B. This creates the premise of an eloquent study in terms of identifying learning styles in relation to age by providing the appropriate ratio between age categories in different schools.

Comparative analysis of learning styles between post-secondary health school a, respective $b$ on age categories

In the next pages we are going to cover the actual results of the research and the meaning towards the scope of this study.

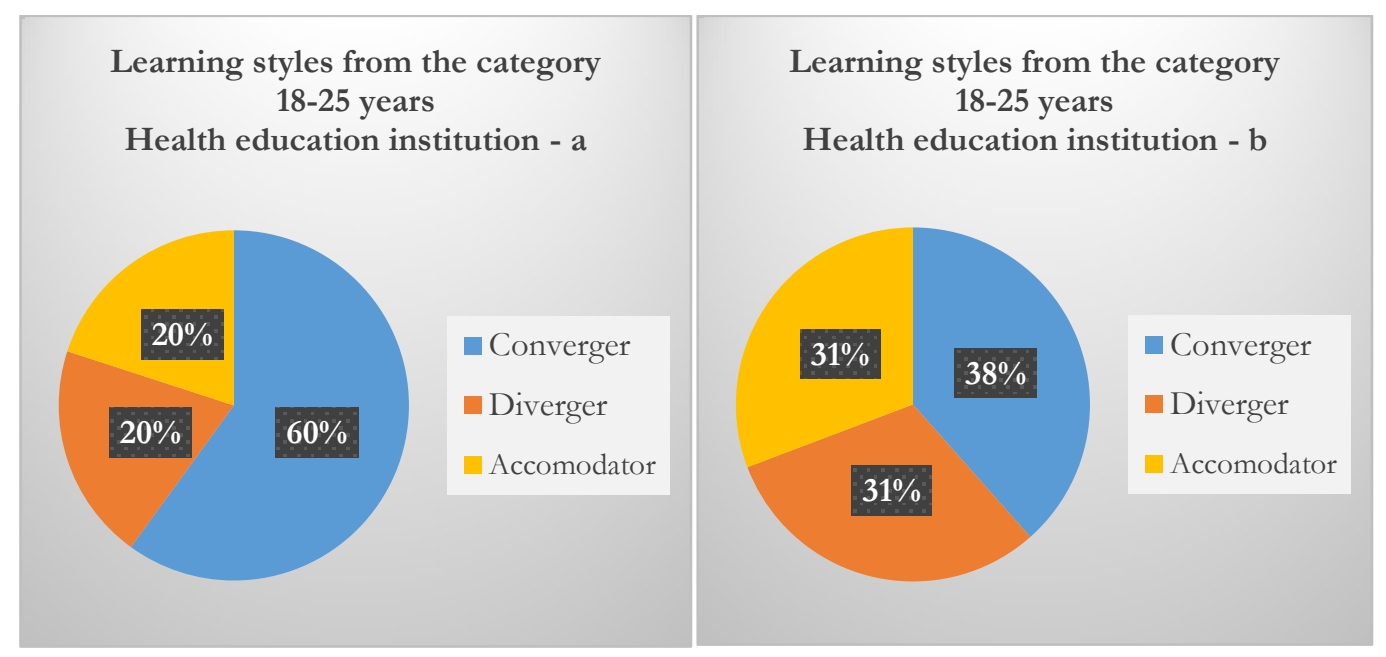

Fig. 1. Learning styles from the category 18-25 years

Source: author's own design

From figure 1 above we can see that in both schools the predominant learning style is the converger one (the percentage for post-secondary health school $\mathrm{A}$ is $60 \%$, and for post-secondary school B - 38\%), people with a learning style oriented towards practice, with problem solving skills and finding solutions for issues. At the same time, the percentages of diverger and accommodator learning styles are equal within schools and similar to each other, which indicates that people have equal preferences for the two styles and also between the schols(percentages are very close). It should be noted that in this age category the assimilative learning style is not in the preferences of any respondent. 


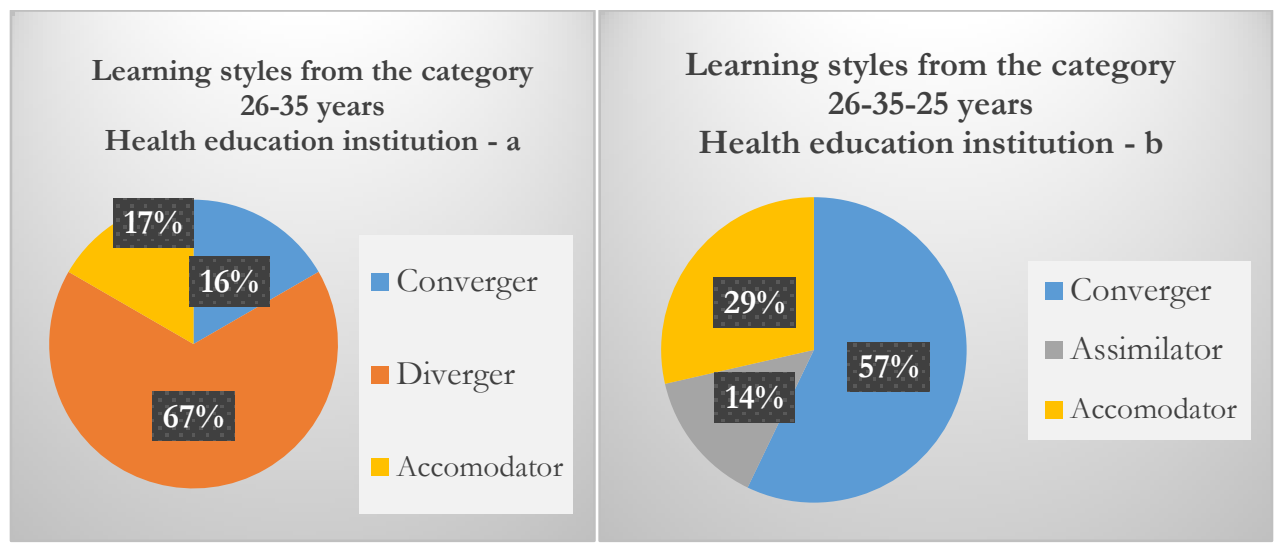

Fig. 2. Learning styles from the category 26-35 years

Source: author's own design

We observe from figure 2 that in the post-secondary health school A the predominant style is the diverger one where it appears that students see concrete situations and prefer to accumulate information (67\%). In the post-secondary health school $\mathrm{B}$, the predominantly identified style is the coverger one, the percentage being $57 \%$. We can highlight the fact that the accommodator style is identified as a second learning style in both schools. We can also see that the predominant learning style in school $\mathrm{A}$ in this age group has a percentage of $0 \%$ in school $\mathrm{B}$, this points out a consistency of age categories fit in school B between the 2 age categories presented, hence the school with less experience of life are leaned to addopt a more practical approach.

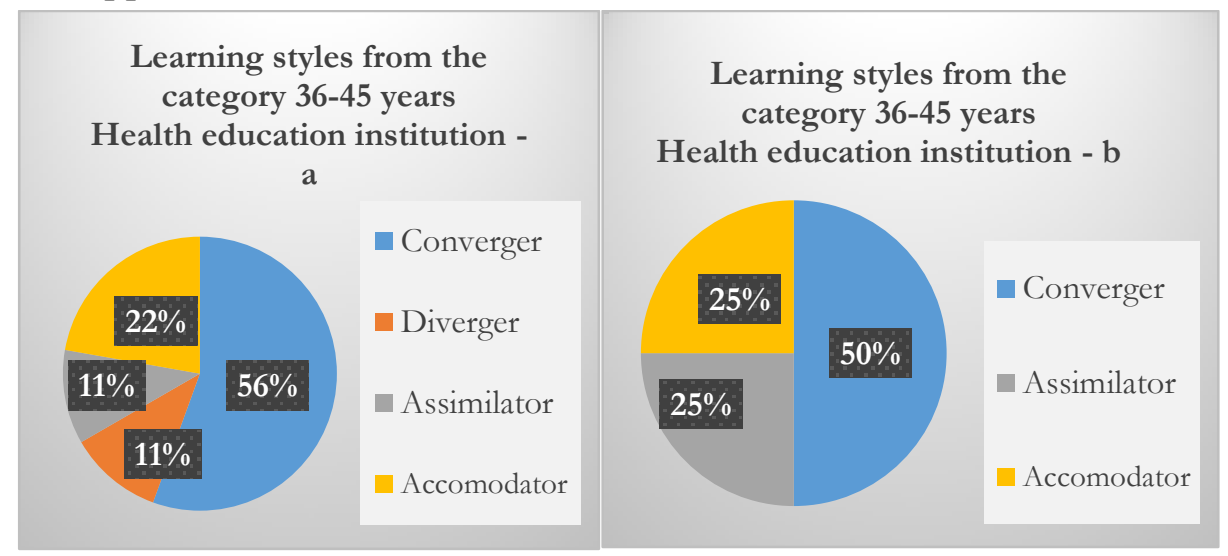

Fig. 3. Learning styles from the category 36-45 years; Source: author's own design

On this category we can see that the style registered in both schools is converger, the percentage being $50 \%$, the other styles being divided approximately equally. The only remark is that the accommodator style has a percentage of over $20 \%$, which shows that these people learn from practical experiences based on instincts and act on the information provided by others. We can notice also that with increased age, the focus shifts from a practical approach style to one based on 
team work and that involves other person's activities to help obtain a more efficient result.

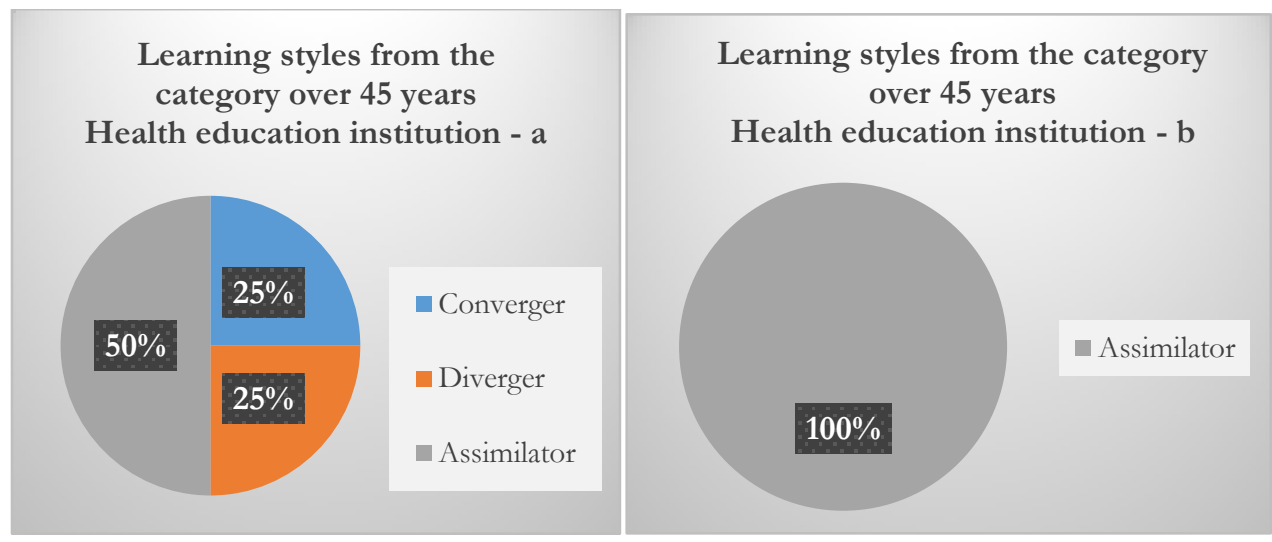

Figure 4. Learning styles from the category over 45 years Source: author's own design

The figure 4 above show that the learning style is assimilator, for both postsecondary health schools over 45 years old participants, this indicates that people over 45 have a tendency due to the experience gained to understand the information received and to order them logically focusing on ideas or concepts in the detriment of personal attachments.

\section{Conclusions}

From the research it can be deduced that the predominant learning style in both post-secondary health schools is the converger style. This style can be found in the post-secondary sanitary school A, in two out of the four age categories, and in the post-secondary sanitary school B it is three times out of four categories. From here we can highlight that the converger style is suitable for the profession of general nurse, because it is associated with activities in the fields like: medicine, computer science, engineering and general science, people who acquire this learning style have a deductive thinking, making prompt decisions in solving various problems.

The second predominant style identified in the studied post-secondary health schools is the assimilator one, people who represent the assimilator style define the problems and plan corrective actions to achieve their activity in optimal conditions. This style has been proved from the study, that comes up with the age, being present in the adults that passed 35 .

From the research we can highlight the fact that in the age category 26-35 years, the diverger style has a majority percentage of $67 \%$, in the post-secondary health school $\mathrm{A}$, while in the post-secondary health school B it was not identified as the predominant style. This is the only difference in terms of learning styles in the schools analyzed in relation to age. The diverger style is directly identified with positions such as: nurse, social worker, psychologist and counselor, much closer to the field of the postsecondary school field of study. This points out to the fact that the persons in school A 
have personality traits closer to the choice of profession made.

From this research it can be concluded that age is not an important factor in belonging to a learning style in post-secondary health schools, but rather with age one can notice a shift from converger style to assimilator, change that is determined by life experience acquired with age.This aspect also goes against the hypothesis form the beginning of the paper emphasizing the fact that age alongside learning style do not have such a big impact in the educational process, but rather depicts a picture of how the educational process has to handled based on a predominant learning style.

Learning styles differ very little in relation to age, and the predominantly identified styles (converger, diverger), have a wide range of professions that can be exercised according to the skills present in each individual's arsenal, starting from beginner nurse and advancing hierarchically to the position of director of health care.

In our opinion the learning styles are influenced in a bigger or smaller proportion by factor like age, environment and others. Learning styles should be used more frequent in the educational process, by creating adaptive courses for developing certain critical skills in creating future generations with proper knowledge in key domains, amongst which we can find also the medical one. We also consider that learning styles are used to little among the educational institution and are oftenly overlooked when the educational strategy is developed and implemented. Allowing more importance to the learning styles of each institution's students could lead to making learning easier and more in reach for every category of persons regardless of the external factors (age, environment and others).

The research can be extended by applying a questionnaire to a larger number of respondents, in a larger number of schools, also other reference categories can be introduced: environment of origin, marital status, studies, etc., and it can also be expanded for the number of schools at regional, national and international level.

\section{References}

Bălan, B., Boncu, Ş., Cosmovici, A., Cozma, T., Crețu, C., Cucoş, C., (coord), Moise, C., Momanu, M., Neculau, A., \& Rudica, T. (2005). Psihopedagogie pentru examenele de definitivare şi grade didactice [Psychopedagogy for final exams and teaching degrees.] . Polirom.

Ciesielski, M.L. (2009). Aspecte ale educației adulților [Aspects of adult education]. http://www.sinuc.utilajutcb.ro/IV.8.pdf

City of Bunbury (2019). Kolb, D., Kolb's Learning Style Questionnaire. www.bunbury.wa.gov.au

Kolb, D. A., (1985). Learning-Style Inventory. Self scoring inventory and interpretation booklet. McBer\& Co.

Kolb, A., Kolb, D. (2018). Eight important things to know about The Experiential Learning Cycle. AEL 40(3), 8-13. https:// search.informit.org/doi/10.3316/informit.192540196827567

Kolb, D. (1984). Experiential learning: Experience as the source of learning and development. PrenticeHall. 
Cristina VIRAG-IORGA et al. | Lumen Proceedings 17 | WLC 2021

McLeod, S. A. (2017). Kolb - learning styles and experiential learning cycle. Simply Psychology. https://www.simplypsychology.org/learning-kolb.html

Negovan, V. (2008). Psihologia educației [Psychology of Education]. CREDIS.

Sălăvăstru, D. (2004). Psihologia educației [Psychology of Education]. Polirom. 